\title{
The Importance of L-Rhamnose Sugar
}

\author{
Hüseyin Kahraman* \\ Department of Biology, Faculty of Art and Sciences, Inonu University, Malatya 44280, Turkey \\ *Corresponding author: Hüseyin Kahraman, Department of Biology, Faculty of Art and Sciences, Turkey
}

\begin{tabular}{lll}
\hline ARTICLE INFO & & ABSTRACT \\
\cline { 1 - 1 } $\begin{array}{l}\text { Received: 慧 September 16, } 2019 \\
\text { Published: }\end{array}$ & & $\begin{array}{l}\text { Citation: Hüseyin Kahraman. The Importance of L-Rhamnose Sugar. Biomed J Sci \& Tech } \\
\text { Res 21(3)-2019. BJSTR. MS.ID.003606. }\end{array}$ \\
\hline
\end{tabular}

\section{Mini Review}

L-Rhamnose (6-deoxy-L-mannose) is a sugar belonging to a deoxy- family commonly found in bacteria and plants (Figure 1). It is now known that L-rhamnose sugar plays an important role in many pathogenic bacteria. Four enzymes are known to be involved in the path of biological synthesis. The crystal structures of two of these have been identified and the other two continue to be studied. This synthesis pathway is not present in humans. Thus, enzymes that functions in this pathway become very attractive for therapeutic intervention [1].

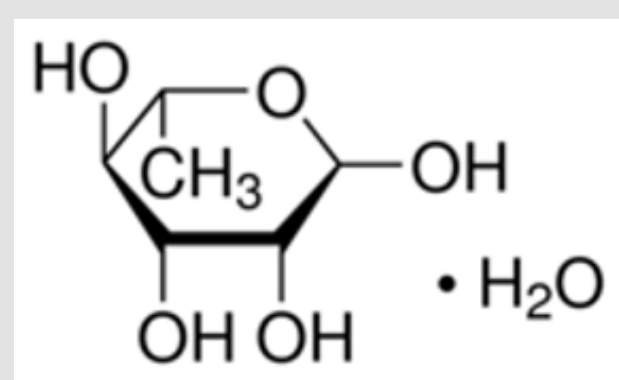

Figure 1: L-Rhamnose monohydrate.

L-rhamnose is chemically in scientific and industrial environments. As it a component in chemical reactions and as a starting material in the synthesis of organic compounds [2].

Hybrid production from polysaccharides has a major disadvantage. Isolated polysaccharides comprise other sugars as well as farnose. Although rhamnose is the result of acid hydrolysis of such polysaccharides, the rhamnose product is often contaminated with other sugars contained in polysaccharides. A second disadvantage stems from the inherent polysaccharide property. If selected microbial strains for exo-polysaccharide production are

used as the source of rhamnose-containing polysaccharide, release of the polysaccharide to the growth medium results in a high viscosity culture. A final disadvantage is that the polysaccharides released by the microbial cells into the culture medium are generally purified together with the protein components. These protein contaminants require the use of additional purification steps prior to hydrolysis of the polysaccharide. Upon isolation of polysaccharides from plants or bacteria, processing of polysaccharides requires the use of solvents for dissolution. This polysaccharide-solvent mixture is ultimately a highly viscous material which is difficult to process. Therefore, all problems associated with the processing of rhamnose from polysaccharides may make this approach suitable for largescale production [2].

L-Rhamnose isomerase (L-RI, EC: 5.3.1.14) catalyzes the isomerisation between L-Rhamnose and L-Rhamnolose plays an important role in microbial L-Rhamnose metabolism. This phenomenon occurs in a wide range of microorganisms. Rhamnose is gaining increasing attention due to its broad substrate specificity and its great potential for enzymatic production of various rare sugars [3]. These L-Rhamnose isomerases are used in the production of rare sugars such as L-spotose, L-mannose, L-talose, D-cellulose, D-allose and L-rhamnulose. However, the use of commercial immobilized bacterial enzymes in the production of rare sugars allows improved stability and better process control [4].

Sugars are of fundamental importance in biochemistry and organic chemistry, and there is great interest in the different types of enzymatic catalyzed reactions in which they are present. L-Rhamnose is also an important component of myco-bacterial cell 
walls. The metabolic pathway for the breakdown of L-Rhamnose in Escherichia coli is similar to that of glucose-6-phosphate in the glycolysis pathway [5].

Oligo- and polysaccharides are ubiquitous components of biological macromolecules and are present as side chains on glycoproteins or as polysaccharides bound to proteins, as in proteoglycans. Many studies have described the structure and function of glycan components of glycoproteins and proteoglycans. A L-Rhamnose specific lectin region has been described on keratinocytes and fibroblasts in human skin. The addition of Rhamnose-Rich Oligo- and Polysaccharides (RROPs) to fibroblasts has been shown to stimulate cell proliferation and increase extracellular matrix biosynthesis, and this lectin region acts as a "real" receptor that transmits messages into the cell [6].

In addition, they combine with lipids to form structures called rhamnolipids (Figure 2). This molecule forms the basis of biosurfactant production, especially in P. aeruginosa. L-Rhamnose is an open-ended study subject too many study. This molecule reduces surface and interface tensions. Therefore, they offer excellent emulsifying/solubilizing, foaming and dispersing properties. Since they are biodegradable, they are particularly suitable for biological reproduction. It also has a protective side by joining the biofilm structure [7]. Studies with rhamnose will open the way for the discovery of new features.

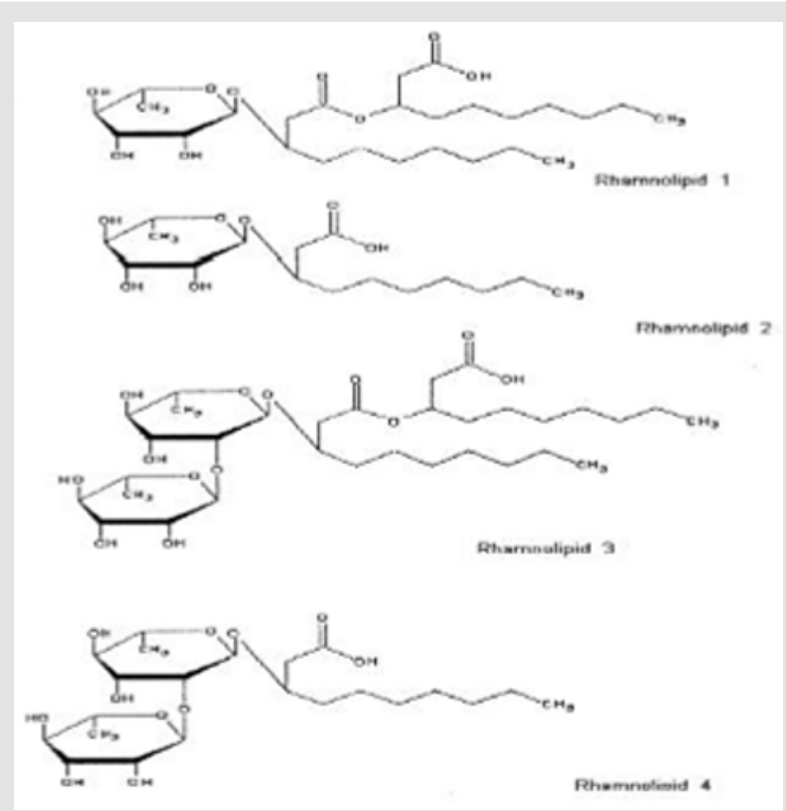

Figure 2: Rhamnolipids [8].

\section{References}

1. Giraud MF, Naismith JH (2000) The rhamnose pathway. Curr Opin Struct Biol 10(6): 687-696.

2. Linhardt RJ, Bakhit R, Daniels L, Mayerl F, Pickenhagen W (1989) Microbially Produced Rhamnolipid as a Source of Rhamnose. Biotechnol Bioeng 33(3): 365-368.

3. Xu W, Zhang W, Zhang T, Jiang B, Mu W (2016) L-Rhamnose isomerase and its use for biotechnological production of rare sugars. Appl Microbiol Biotechnol 100(7): 2985-2992.

4. Kim YS, Kim DY, Park CS (2017) Production of L-rhamnulose, a rare sugar from L-rhamnose using commercial immobilized glucose isomerase. Biocat Biotrans 36(6): 417-421.
5. Korndörfer IP, Fessner WD, Matthews BW (2000) The structure of rhamnose isomerase from Escherichia coli and its relation with xylose isomerase illustrates a change between inter and intra-subunit complementation during evolution. J Mol Biol 300(4): 917-933.

6. Faury G, Ruszova E, Molinari J, Mariko B, Raveaud S, et al. (2008) The $\alpha$-LRhamnose recognizing lectin site of human dermal fibroblasts functions as a signal transducer Modulation of $\mathrm{Ca} 2+$ fluxes and gene expression. Biochimica et Biophysica Acta, 1780(12): 1388-1394.

7. Pinzon NM, Ju LK (2009) Improved detection of rhamnolipid production using agar plates containing methylene blue and cetyl trimethylammonium bromide. Biotechnol Lett 31: 1583-1588.

8. Tahzibi A, Kamal F, Assadi MM (2004) Improved production of rhamnolipids by a Pseudomonas aeruginosa mutant. Iran Biomed J 8 (1): 25-31. 
ISSN: 2574-1241

DOI: 10.26717/BJSTR.2019.21.003606

Hüseyin Kahraman. Biomed J Sci \& Tech Res

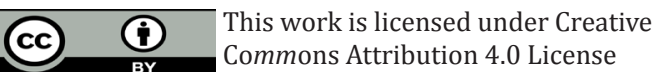

Submission Link: https://biomedres.us/submit-manuscript.php

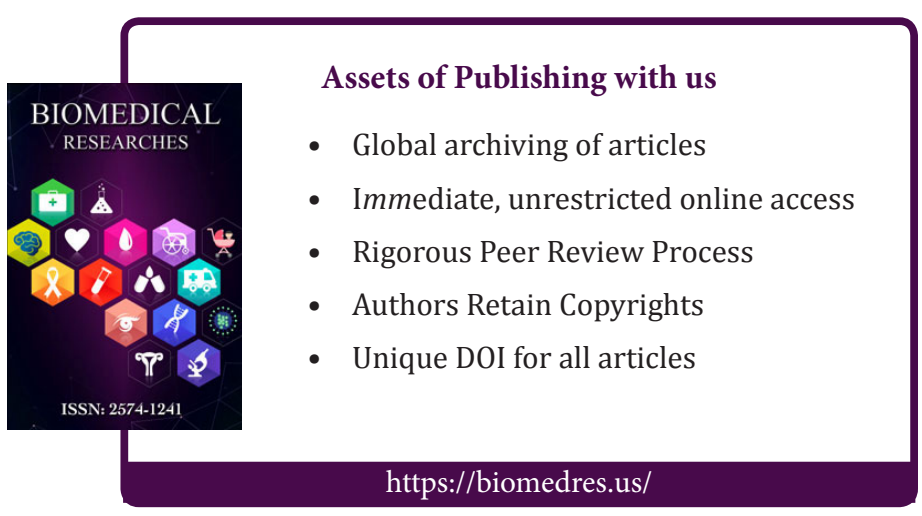

